\title{
Plasma S100A12 Levels and Peripheral Arterial Disease in End-Stage Renal Disease
}

\author{
Yayoi Shiotsu $^{a} \quad$ Yasukiyo Mori $^{a} \quad$ Tsuguru Hatta $^{\mathrm{b}}$ Noboru Makic \\ Kumiko lida ${ }^{c}$ Eiko Matsuoka ${ }^{a}$ Hiroshi Kado $^{a}$ Ryo Ishida ${ }^{a}$ \\ Noriko Kishimoto $^{a}$ Keiichi Tamagaki ${ }^{a}$ Masato Nishimurad \\ Noriyuki Iwamotod ${ }^{d}$ Toshihiko Ono $^{d}$ Hiroaki Matsubara ${ }^{a}$ \\ Atsushi Kosaki \\ a Department of Cardiology and Nephrology, Kyoto Prefectural University of Medicine, \\ Kyoto, ${ }^{\mathrm{b}}$ Renal Division, Omihachiman Community Medical Center, Omihachiman, \\ 'Advanced Life Science Institute, Saitama, 'Cardiovascular Division, Tojinkai Hospital, \\ Kyoto, and ${ }^{e}$ Department of Medicine II, Kansai Medical University, Hirakata, Japan
}

\section{Key Words}

S100A12 $\cdot$ Peripheral arterial disease $\cdot$ Chronic kidney disease $\cdot$ Receptor for advanced glycation end products

\begin{abstract}
Background: S100A12 is an endogenous ligand of the receptor for advanced glycation end products (RAGE). Plasma S100A12 levels are high in end-stage renal disease (ESRD) patients undergoing maintenance hemodialysis (HD). Peripheral arterial disease (PAD) is common in HD patients and is associated with increased cardiovascular morbidity and mortality rates in this population. To date, however, no study has specifically assessed the relationship between plasma S100A12 and PAD in HD patients. Methods: We conducted a cross-sectional study of 152 HD patients in our affiliated hospital. We investigated PAD history and patient characteristics and quantified plasma S100A12 levels in all participants. Results: HD patients with PAD $(n=26 ; 21.9$ [13.6-33.4] ng/ml) showed significantly higher plasma S100A12 levels than HD patients without

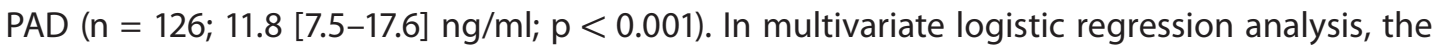
plasma S100A12 level (odds ratio [OR] 5.71; 95\% confidence interval [CI] 1.29-25.3; $p=0.022$ ) was identified as an independent factor associated with PAD prevalence. Another factor associated
\end{abstract}


with PAD prevalence was the ankle-brachial index (OR 0.54; 95\% Cl 0.40-0.74; $\mathrm{p}<0.001$ ). Conclusion: These results suggest that plasma S100A12 levels are strongly associated with PAD prevalence in ESRD patients undergoing HD.

Copyright $\odot 2011$ S. Karger AG, Basel

\section{Introduction}

Peripheral arterial disease (PAD) is a strong predictor of subsequent all-cause and cardiovascular mortality in end-stage renal disease (ESRD) patients $[1,2]$. Therefore, assessment and prevention of PAD are becoming major considerations for managing ESRD patients. Traditional risk factors for atherosclerotic cardiovascular diseases (CVDs), such as smoking, diabetes, hyperlipidemia, and hypertension, are associated with PAD in the general population [3]. Few studies have examined the relationship between traditional risk factors for CVD and PAD in ESRD $[4,5]$. Traditional risk factors in the general population, such as diabetes and tobacco abuse, are also associated with PAD in dialysis patients [5]. In the Dialysis Outcomes and Practice Patterns Study [6], male sex, diabetes, hypertension, and smoking together with dialysis duration were significantly associated with PAD. However, these CVD risk factors are unlikely to completely explain the high PAD prevalence in chronic kidney disease (CKD) subjects because the association of CKD with PAD remains consistently strong following adjustment for these and other factors [7]. This suggests that some components of the uremic environment may contribute to PAD development or progression [8]. Non-traditional risk factors, such as oxidative stress and advanced glycation end products (AGEs) in combination with receptors for AGE (RAGE), have been emphasized as factors associated with atherosclerosis that may play an important role in CVD development in CKD patients [9].

Enhanced RAGE expression has been observed in the peripheral blood monocytes of CKD patients, suggesting that RAGE may amplify ligand-induced monocyte perturbation and contribute to monocyte-mediated vascular inflammation in these patients [10]. AGEs were initially believed to be the main active ligands for RAGE, but subsequently, several other ligands for RAGE including S100A12, high mobility group box proteins, and amyloid fibrils have been identified [11].

Of the endogenous ligands for RAGE, emerging evidence from in vitro and in vivo studies supports a role for S100A12, formerly called EN-RAGE, in chronic inflammation leading to several pathogenic conditions such as atherosclerosis $[12,13]$. Therefore, the binding of RAGE to S100A12 may further promote underlying inflammation in atherosclerosis and its related manifestations such as PAD.

Based on cross-sectional analyses of PAD in 152 ESRD patients undergoing hemodialysis (HD), we here assessed the relationship between plasma S100A12 levels and PAD in ESRD.

\section{Subjects and Methods}

\section{Patients}

All procedures were performed in accordance with the guidelines of the Declaration of Helsinki on Human Experimentation. The study was approved by the Ethics Committees on Human Research at our institutions, and all subjects provided informed consent. Demographic and medical data including age, sex, smoking history, and comorbid conditions were obtained from medical records.

The subjects were 152 ESRD patients undergoing HD who had relevant clinical information. Patients with clinical evidence of malignant diseases or overt infection were ex- 
Fig. 1. Distribution of peripheral arterial disease (PAD) in the study participants. An overlap was observed between coronary artery disease (CAD), stroke, and PAD. The PAD group represents patients with PAD, those with PAD and CAD, and those with PAD, CAD, and stroke.

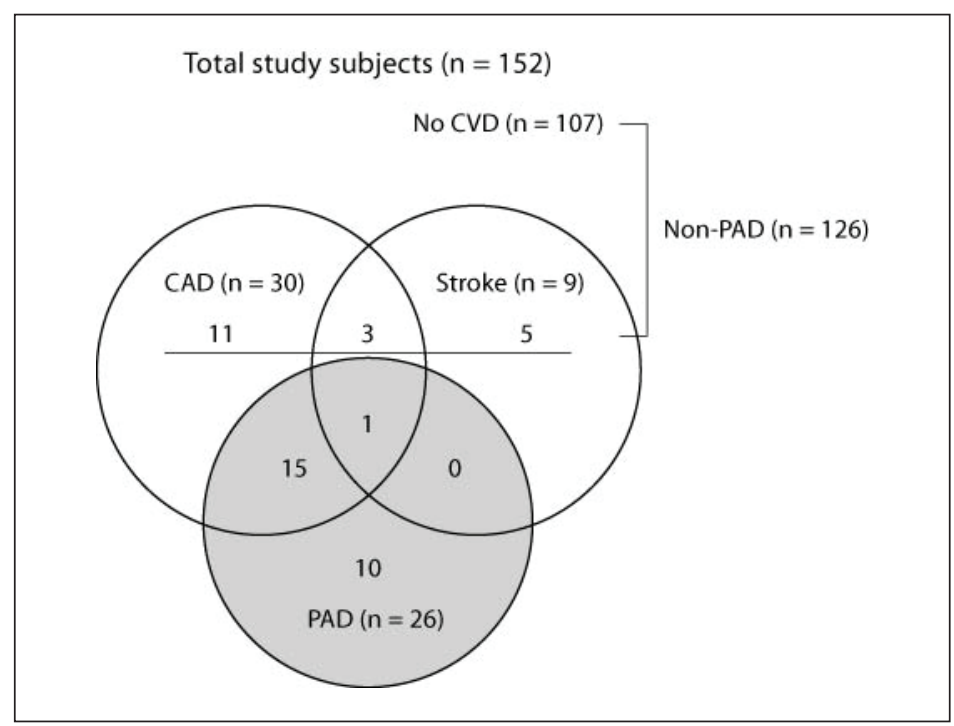

cluded. All participants received conventional dialysis treatment for 3-4 h thrice a week, with a standard bicarbonate dialysis solution. An ankle-brachial index (ABI) measurement was performed on all HD patients as part of a routine clinical protocol in our affiliated hospital. PAD diagnosis was based on clinical symptoms, such as intermittent claudication or critical limb ischemia with rest pain, ulcers, and gangrene (Fontaine stages II-IV); these findings were subsequently verified by computed tomography angiography and/or lower limb angiography. Patients with a history of percutaneous transluminal angioplasty, bypass grafting, and/or amputation for PAD were also included. Complaints such as numbness, tingling, or weakness of the lower extremities were not included as PAD symptoms because it was difficult to distinguish them from the symptoms of peripheral neuropathy. Symptoms caused by orthopedic diseases were also excluded. Coronary artery disease (CAD) was defined as ischemic heart disease including myocardial infarction diagnosed on the basis of elevated levels of cardiac enzymes and/or typical electrocardiography changes and angina pectoris diagnosed by typical electrocardiography changes without elevated cardiac enzymes and coronary intervention (percutaneous coronary intervention or coronary artery bypass grafting). Stroke diagnosis was based on clinical symptoms verified by computed tomography and/or magnetic resonance imaging. The endpoints committee for this study verified the above-mentioned criteria for $\mathrm{PAD}, \mathrm{CAD}$ and stroke in each participant. We investigated the medical history of all participants to diagnose PAD on the basis of the abovementioned criteria.

Finally, we enrolled 26 patients with PAD (PAD alone, $\mathrm{n}=10$; PAD with CAD, $\mathrm{n}=15$; and PAD with CAD and stroke, $\mathrm{n}=1$ ) (fig. 1). To determine the relationship between plasma S100A12 levels and PAD, patients with a clinical history of other CVDs, such as CAD and/ or stroke without PAD, were carefully excluded from the PAD group and included in the non-PAD group (CAD alone, $n=11$; stroke alone, $n=5$; and CAD with stroke, $n=3$ ) (fig. 1).

\section{Laboratory Methods}

Blood samples were obtained via vascular access when dialysis was started on a midweek routine dialysis day. The plasma was then immediately frozen and stored at $-80^{\circ} \mathrm{C}$ until the time of assay. The levels of urea nitrogen, serum creatinine, total cholesterol, albumin, hemoglobin, calcium, and phosphate as well as white blood cell and platelet counts were mea- 
Fig. 2. Plasma S100A12 levels in hemodialysis (HD) patients. HD patients with PAD had significantly higher plasma S100A12 levels than HD patients without PAD (21.9 [13.6-33.4] ng/ml vs. 11.8 [7.517.6] $\mathrm{ng} / \mathrm{ml}, \mathrm{p}<0.001)$.

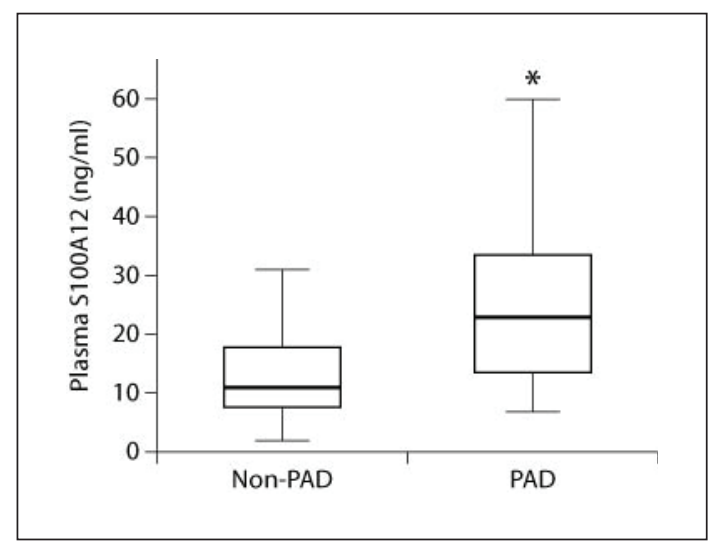

sured using standard clinical laboratory methods. High-sensitivity C-reactive protein (hsCRP) was measured using an automatic analyzer (TBA-120FR; Toshiba, Tokyo, Japan).

\section{ELISA for S100A12 Quantification}

A sandwich assay was performed using hCF128 monoclonal antibodies to quantify plasma S100A12 levels [14]. Plasma S100A12 levels in the samples were determined by interpolation of absorbance values from a calibration curve. In our previous study [15], the mean \pm SD plasma S100A12 level in 42 healthy subjects (29\% male; mean age 50.5 years) was $10.8 \pm$ $6.3 \mathrm{ng} / \mathrm{ml}$.

\section{Statistical Analysis}

The results were expressed as mean $\pm \mathrm{SD}$. Variables with a skewed distribution were expressed as median and interquartile range (25th-75th percentiles). Group differences were analyzed using Student's t test, the Mann-Whitney U test, and $\chi^{2}$ test for normally distributed, non-normally distributed, and discontinuous variables, respectively. Univariate logistic regression analysis was performed to determine factors contributing to PAD. In this analysis, variables with a skewed distribution (plasma S100A12 and hs-CRP levels) were log transformed. Variables significantly associated with PAD prevalence were included in multivariate logistic regression analysis. All statistical analyses were performed using SPSS 17.0 for Windows (IBM Japan, Tokyo, Japan). $\mathrm{p}<0.05$ was considered statistically significant.

\section{Results}

\section{Study Population}

The study subjects were 152 ESRD patients receiving maintenance HD at our affiliated hospital (43.4\% male; mean age 65.4 years; mean HD duration 10 years). The underlying renal disorders comprised diabetic nephropathy (DN) (25\%) and non-diabetic renal diseases including chronic glomerulonephritis, hypertensive nephrosclerosis, polycystic kidney disease, and diseases of unknown etiology (75\%). PAD was observed in 26 patients (17.1\%; fig. 1 ). The clinical characteristics of the patients are summarized in table 1.

Higher Plasma S100A12 Levels in HD Patients with PAD

$\mathrm{HD}$ patients with PAD had significantly higher plasma S100A12 levels than HD patients without PAD (21.9 [13.6-33.4] ng/ml vs. 11.8 [7.5-17.6] ng/ml; p <0.001) (table 1, fig. 2). ABI, 
Table 1. Clinical characteristics and plasma S100A12 levels of the study groups

\begin{tabular}{|c|c|c|c|c|}
\hline & $\begin{array}{l}\text { All } \\
(\mathrm{n}=152)\end{array}$ & $\begin{array}{l}\text { PAD } \\
(n=26)\end{array}$ & $\begin{array}{l}\text { Non-PAD } \\
(\mathrm{n}=126)\end{array}$ & $\mathrm{p}$ value $\mathrm{a}^{\mathrm{a}}$ \\
\hline Age, years & $65.4 \pm 12.2$ & $71.2 \pm 9.8$ & $63.9 \pm 13.0$ & 0.007 \\
\hline Male/female, $\mathrm{n}$ & $66 / 86$ & $8 / 18$ & $58 / 68$ & 0.153 \\
\hline Current smoker/non-smoker, $\mathrm{n}$ & $14 / 138$ & $3 / 23$ & $11 / 115$ & 0.441 \\
\hline Duration of HD, years & $10.0 \pm 7.9$ & $8.6 \pm 7.1$ & $10.3 \pm 8.1$ & 0.311 \\
\hline Systolic BP, mm Hg & $143.0 \pm 23.2$ & $145.2 \pm 20.8$ & $142.5 \pm 23.8$ & 0.587 \\
\hline Hemoglobin, g/l & $100 \pm 10$ & $100 \pm 10$ & $101 \pm 11$ & 0.731 \\
\hline White blood cells, $\times 10^{9} / 1$ & $6 \pm 2$ & $6 \pm 2$ & $6 \pm 2$ & 0.665 \\
\hline Platelet, $\times 10^{9} / 1$ & $167 \pm 59$ & $165 \pm 57$ & $168 \pm 59$ & 0.833 \\
\hline hs-CRP, mg/l & $1.0(0.4-3.0)$ & $1.7(1.0-4.3)$ & $0.9(0.4-2.7)$ & 0.882 \\
\hline Creatinine, $\mu \mathrm{mol} / \mathrm{l}$ & $909 \pm 212$ & $866 \pm 234$ & $918 \pm 208$ & 0.019 \\
\hline Albumin, $\mathrm{g} / \mathrm{l}$ & $35 \pm 4$ & $35 \pm 2$ & $35 \pm 4$ & 0.616 \\
\hline Sodium, mmol/l & $140 \pm 3$ & $139 \pm 3$ & $140 \pm 3$ & 0.049 \\
\hline Potassium, $\mathrm{mmol} / \mathrm{l}$ & $4.7 \pm 0.7$ & $4.6 \pm 0.8$ & $4.8 \pm 0.7$ & 0.343 \\
\hline Adjusted calcium, mmol/l & $2.32 \pm 0.16$ & $2.29 \pm 0.02$ & $2.32 \pm 0.17$ & 0.395 \\
\hline Phosphate, $\mathrm{mmol} / \mathrm{l}$ & $1.54 \pm 0.39$ & $1.57 \pm 0.46$ & $1.53 \pm 0.37$ & 0.635 \\
\hline Calcium, $\mathrm{mmol} / \mathrm{l} \times$ phosphate, $\mathrm{mmol} / \mathrm{l}$ & $3.38 \pm 0.94$ & $3.41 \pm 1.04$ & $3.38 \pm 0.92$ & 0.881 \\
\hline Total cholesterol, $\mathrm{mmol} / 1^{1}$ & $4.61 \pm 1.56$ & $4.59 \pm 1.36$ & $4.62 \pm 1.60$ & 0.920 \\
\hline $\mathrm{DN} /$ non-DN, n & $38 / 114$ & $12 / 14$ & $26 / 100$ & 0.006 \\
\hline ABI & $1.11 \pm 0.18$ & $0.93 \pm 0.23$ & $1.15 \pm 0.15$ & $<0.001$ \\
\hline ba $\mathrm{PWV}, \mathrm{cm} / \mathrm{s}$ & $1,839 \pm 516$ & $1,950 \pm 593$ & $1,817 \pm 499$ & 0.239 \\
\hline Plasma S100A12, ng/ml & $12.3(7.8-20.0)$ & $21.9(13.6-33.4)$ & $11.8(7.5-17.6)$ & $<0.001$ \\
\hline
\end{tabular}

Unless indicated otherwise, values are mean \pm SD or median with 25th-75th percentiles shown in parentheses.

$\mathrm{PAD}=$ Peripheral arterial disease $\mathrm{HD}=$ hemodialysis; $\mathrm{BP}=$ blood pressure; hs-CRP = high-sensitivity C-reactive protein; $\mathrm{DN}=$ diabetic nephropathy; $\mathrm{CVD}=$ cardiovascular disease; $\mathrm{ABI}=$ ankle-brachial index; ba PWV = brachial-ankle pulse wave velocity.

a PAD versus non-PAD.

DN prevalence, age, serum sodium and creatinine levels were statistically different between the PAD and non-PAD groups.

Association between Plasma S100A12 Levels and PAD

Univariate logistic regression analysis used to determine the contributing factor for PAD showed that plasma S100A12 levels, ABI, DN prevalence, hs-CRP levels, and age were significantly associated with PAD prevalence (table 2). Furthermore, multivariate logistic regression analysis with the above-mentioned factors showed the plasma S100A12 level (odds ratio $[\mathrm{OR}] 5.71$; 95\% confidence interval $[\mathrm{CI}] 1.29-25.3 ; \mathrm{p}=0.022$ ) to be an independent factor associated with PAD prevalence (table 3). Another independent factor associated with PAD prevalence was ABI (OR 0.54; 95\% CI 0.40-0.74; $\mathrm{p}<0.001$ ).

To determine the relationship between the plasma S100A12 level and PAD, all subjects were categorized by tertiles of the plasma S100A12 level. As shown in table 4, after multiple adjustments with the significant factors in univariate logistic analysis (ABI, DN prevalence, hs-CRP levels, and age), a higher plasma S100A12 level was found to be correlated with an increased risk of PAD. Compared with patients in the first tertile, the PAD risk was significantly higher in patients in the second (OR 6.49; 95\% CI 1.10-38.4; $\mathrm{p}=0.014$ ) and third quartiles (OR 13.7; 95\% CI 2.34-80.4; $\mathrm{p}=0.004$ ). 
Table 2. Univariate logistic regression analysis of clinical parameters and PAD

\begin{tabular}{|c|c|c|c|}
\hline & OR & $95 \% \mathrm{CI}$ & $\mathrm{p}$ value \\
\hline Age, years & 1.06 & $1.02-1.10$ & $0.009^{*}$ \\
\hline Male & 0.52 & $0.21-1.29$ & 0.157 \\
\hline Current smoker & 1.37 & $0.35-5.28$ & 0.653 \\
\hline Duration of HD, years & 0.99 & $0.99-1.00$ & 0.280 \\
\hline Systolic BP, mm Hg & 1.01 & $0.99-1.02$ & 0.584 \\
\hline Hemoglobin, g/l & 1.01 & $0.97-1.05$ & 0.729 \\
\hline White blood cells, $\times 10^{9} / 1$ & 1.00 & $1.00-1.00$ & 0.663 \\
\hline Platelet, $\times 10^{9} / 1$ & 0.99 & $0.99-1.01$ & 0.831 \\
\hline hs-CRP, /log mg/l & 2.23 & $1.07-4.67$ & $0.033^{*}$ \\
\hline Creatinine, $\mu \mathrm{mol} / \mathrm{l}$ & 0.99 & $0.99-1.01$ & 0.257 \\
\hline Albumin, g/l & 0.98 & $0.87-1.10$ & 0.711 \\
\hline Sodium, $\mathrm{mmol} / \mathrm{l}$ & 0.85 & $0.73-1.00$ & 0.053 \\
\hline Potassium, $\mathrm{mmol} / \mathrm{l}$ & 0.74 & $0.40-1.37$ & 0.341 \\
\hline Adjusted calcium, mmol/l & 0.29 & $0.07-4.99$ & 0.393 \\
\hline Phosphate, $\mathrm{mmol} / \mathrm{l}$ & 1.30 & $0.44-3.86$ & 0.633 \\
\hline Calcium, $\mathrm{mmol} / \mathrm{l} \times$ phosphate, $\mathrm{mmol} / \mathrm{l}$ & 1.04 & $0.66-1.62$ & 0.880 \\
\hline Total cholesterol, $\mathrm{mmol} / \mathrm{l}$ & 0.99 & $0.75-1.30$ & 0.919 \\
\hline $\mathrm{DN}$ & 3.30 & $1.36-7.98$ & $0.008^{*}$ \\
\hline ABI, 0.1 unit & 0.52 & $0.39-0.68$ & $<0.001^{*}$ \\
\hline ba PWV, $\mathrm{cm} / \mathrm{s}$ & 1.00 & $1.00-1.00$ & 0.241 \\
\hline Plasma S100A12, /log ng/ml & 9.24 & $2.89-29.58$ & $<0.001^{*}$ \\
\hline
\end{tabular}

$\mathrm{PAD}=$ Peripheral arterial disease; $\mathrm{OR}=$ odds ratio; $95 \% \mathrm{CI}=95 \%$ confidence interval; $\mathrm{HD}=$ hemodialysis; $\mathrm{BP}=$ blood pressure; hs-CRP = high-sensitivity C-reactive protein; $\mathrm{DN}=$ diabetic nephropathy; $\mathrm{ABI}=$ ankle-brachial index; ba PWV = brachial-ankle pulse wave velocity. ${ }^{*}$ Significant independent factors.

Table 3. Multivariate logistic regression analysis of clinical parameters and PAD

\begin{tabular}{lccc}
\hline & OR & $95 \%$ CI & p value \\
\hline Age, years & 1.01 & $0.95-1.07$ & 0.905 \\
hs-CRP, /log mg/l & 1.74 & $0.63-4.82$ & 0.288 \\
DN & 1.98 & $0.65-5.97$ & 0.228 \\
ABI, 0.1 unit & 0.54 & $0.40-0.74$ & $<0.001^{*}$ \\
Plasma S100A12, /log ng/ml & 5.71 & $1.29-25.3$ & $0.022^{*}$ \\
\hline
\end{tabular}

$\mathrm{PAD}=$ Peripheral arterial disease; $\mathrm{OR}=$ odds ratio; $95 \% \mathrm{CI}=95 \%$ confidence interval; hs- $\mathrm{CRP}=$ high sensitivity C-reactive protein; DN = diabetic nephropathy; ABI =ankle-brachial index. * Significant independent factors.

\section{Discussion}

We studied 152 patients undergoing maintenance HD. HD patients with PAD had significantly higher plasma S100A12 levels than HD patients without PAD. Plasma S100A12 levels were identified as an independent factor associated with PAD prevalence. These findings suggest a correlation between S100A12 and PAD in ESRD.

PAD is common in dialysis patients, with a prevalence of approximately $15 \%$ [16]. CKD is associated with an increased PAD risk and recognition of this risk is growing $[17,18]$. How- 
Table 4. Multivariate logistic regression analysis of PAD prevalence by tertiles of plasma S100A12 levels in $152 \mathrm{HD}$ patients

\begin{tabular}{llll}
\hline S100A12 & $\mathrm{n}$ & OR $(95 \% \mathrm{CI})$ & $\mathrm{p}$ value \\
\hline Tertile $1(<9.3 \mathrm{ng} / \mathrm{ml})$ & 51 & 1.0 & \\
Tertile 2 $(9.3-16.7 \mathrm{ng} / \mathrm{ml})$ & 52 & $6.49(1.10-38.4)$ & $0.014^{*}$ \\
Tertile 3 $(>16.7 \mathrm{ng} / \mathrm{ml})$ & 49 & $13.7(2.34-80.4)$ & $0.004^{*}$ \\
\hline
\end{tabular}

The values are adjusted for age, hs-CRP, $\mathrm{ABI}$ and the presence of diabetes mellitus. PAD = Peripheral arterial disease; $\mathrm{HD}=$ hemodialysis; $\mathrm{OR}=$ odds ratio; $95 \% \mathrm{CI}=95 \%$ confidence interval; hs-CRP = highsensitivity C-reactive protein; ABI =ankle-brachial index. ${ }^{*}$ Significant independent factors versus tertile 1.

ever, the reasons underlying the increased incidence of PAD in the CKD population remain unclear. Very few data are available regarding the possible association of PAD with novel CVD risk factors in CKD patients. The pathogenesis of atherosclerosis including PAD in the general population is characterized by the presence of subclinical chronic inflammation [3]. Chronic inflammation is a common feature of CKD, and approximately $30-50 \%$ of ESRD patients provide serological evidence [19].

S100A12 is as a potent chemoattractant; its binding to RAGE expressed by endothelial cells, mononuclear phagocytes, and lymphocytes triggers cellular activation and the generation of key proinflammatory mediators such as interleukin- $1 \beta$ and tumor necrosis factor- $\alpha$ [20]. In the ESRD population, we found that the mean plasma S100A12 levels of $72 \mathrm{HD}$ patients were 2.3-fold higher than those of control subjects. Furthermore, the maximum intima-media thickness of the carotid artery correlated with plasma S100A12 levels in HD patients [15]. Subsequently, a larger study conducted by our group showed that plasma S100A12 levels were higher in $550 \mathrm{HD}$ patients than in healthy subjects and that this level was an independent factor associated with CVD prevalence [21]. Moreover, in their ad hoc analysis of 184 prevalent HD patients, Nakashima et al. [22] found that the S100A12 level was a direct predictor of all-cause and CVD mortality, even after an adjustment for confounding variables. An animal study using transgenic overexpression of human S100A12 in murine vascular smooth muscle clearly demonstrated the critical role of S100A12 in directly mediating enhanced production of reactive oxidative species and cytokine production, leading to enhanced atherosclerosis in ApoE null mice [13]. These results indicate that plasma S100A12 levels may reflect chronic inflammation-mediated CVD. Our current analysis also supports a specific role of S100A12 in the development and/or progression of PAD in ESRD patients undergoing HD.

Some limitations of this study must be acknowledged. Firstly, the study had a cross-sectional design, which limited our ability to establish causal relationships. However, a recent experimental study reported an underlying relationship between S100A12 and atherosclerosis in CKD. Using S100A12 transgenic mice with surgically induced CKD, Gawdzik et al. [23] showed that S100A12 overexpression caused atherogenesis with increased expression of an osteoblastic gene in vascular smooth muscle cells. Secondly, other possible novel risk factors for PAD in CKD, such as $\mathrm{Lp}(\mathrm{a})$ and homocysteine levels, might be important and unfortunately were not measured in our study. Thirdly, although ABI is a simple, non-invasive, reliable test for the general population and PAD is traditionally defined by an ABI of $\leq 0.9$ [3], ABI has been suggested to be unsuitable for assessing PAD in ESRD patients [24]. Increased arterial stiffness might interfere with ABI measurements and affect the sensitivity of ABI in detecting PAD among HD patients. Therefore, PAD diagnosis in this study was not based on ABI measurements but on clinical symptoms endorsed by an imaging study. However, this might underestimate the existence of subclinical PAD [25]. Fourthly, although 10 of 26 PAD patients in this 
study had no clinical symptoms with positive imaging study of CAD and/or stroke, subclinical atherosclerotic lesions in addition to PAD might be co-existing, affecting the value of plasma S100A12 levels. Lastly, because we studied a relatively small number of patients, we cannot draw solid conclusions and therefore our findings need to be confirmed by a larger study. Notwithstanding these limitations, emerging reports suggest a role for S100A12 in atherosclerosis $[12,13]$, allowing us to provide a less biased estimate of the relationships observed.

In conclusion, in a study of $152 \mathrm{HD}$ patients, we showed for the first time that the plasma S100A12 level is an independent factor associated with PAD prevalence. We anticipate an important role for S100A12 as a novel biomarker for predicting PAD in ESRD patients. Prospective and interventional studies are ongoing to further clarify the relationship between plasma S100A12 levels and PAD.

\section{Acknowledgements}

We thank Ms. Ikuko Arai for providing the laboratory data and Mr. Hiroshi Omizu for helping with statistical analyses. Part of this study was supported by Grants-in-Aid for Scientific Research from the Japanese Society for the Promotion of Science (No. 20590846) to A.K. and Y.M.

\section{Disclosure Statement}

The authors declare no conflict of interest.

\section{References}

1 Ono K, Tsuchida A, Kawai H, Matsuo H, Wakamatsu R, Maezawa A, Yano S, Kawada T, Nojima Y: Ankle-brachial blood pressure index predicts all-cause and cardiovascular mortality in hemodialysis patients. J Am Soc Nephrol 2003;14:1591-1598.

2 Guerrero A, Montes R, Munoz-Terol J, Gil-Peralta A, Toro J, Naranjo M, Gonzalez-Perez P, MartinHerrera C, Ruiz-Fernandez A: Peripheral arterial disease in patients with stages IV and V chronic renal failure. Nephrol Dial Transplant 2006;21:3525-3531.

3 Hirsch AT, Haskal ZJ, Hertzer NR, Bakal CW, Creager MA, Halperin JL, Hiratzka LF, Murphy WR, et al: ACC/AHA Guidelines for the Management of Patients with Peripheral Arterial Disease (lower extremity, renal, mesenteric, and abdominal aortic): a collaborative report from the American Associations for Vascular Surgery/Society for Vascular Surgery, Society for Cardiovascular Angiography and Interventions, Society for Vascular Medicine and Biology, Society of Interventional Radiology, and the ACC/AHA Task Force on Practice Guidelines (writing committee to develop guidelines for the management of patients with peripheral arterial disease) - summary of recommendations. J Vasc Interv Radiol 2006;17:1383-1397; quiz 1398.

4 O'Hare AM, Hsu CY, Bacchetti P, Johansen KL: Peripheral vascular disease risk factors among patients undergoing hemodialysis. J Am Soc Nephrol 2002;13:497-503.

5 Cheung AK, Sarnak MJ, Yan G, Dwyer JT, Heyka RJ, Rocco MV, Teehan BP, Levey AS: Atherosclerotic cardiovascular disease risks in chronic hemodialysis patients. Kidney Int 2000;58:353-362.

6 Rajagopalan S, Dellegrottaglie S, Furniss AL, Gillespie BW, Satayathum S, Lameire N, Saito A, Akiba T, Jadoul M, Ginsberg N, Keen M, Port FK, Mukherjee D, Saran R: Peripheral arterial disease in patients with end-stage renal disease: observations from the dialysis outcomes and practice patterns study (DOPPS). Circulation 2006;114:1914-1922.

7 Ix JH, Criqui MH: Epidemiology and diagnosis of peripheral arterial disease in patients with chronic kidney disease. Adv Chronic Kidney Dis 2008;15:378-383. 
8 Sarnak MJ, Levey AS, Schoolwerth AC, Coresh J, Culleton B, Hamm LL, McCullough PA, Kasiske BL, Kelepouris E, Klag MJ, Parfrey P, Pfeffer M, Raij L, Spinosa DJ, Wilson PW: Kidney disease as a risk factor for development of cardiovascular disease: a statement from the American Heart Association Councils on Kidney in Cardiovascular Disease, High Blood Pressure Research, Clinical Cardiology, and Epidemiology and Prevention. Circulation 2003;108:2154-2169.

9 Stenvinkel P, Carrero JJ, Axelsson J, Lindholm B, Heimburger O, Massy Z: Emerging biomarkers for evaluating cardiovascular risk in the chronic kidney disease patient: how do new pieces fit into the uremic puzzle? Clin J Am Soc Nephrol 2008;3:505-521.

10 Hou FF, Ren H, Owen WF Jr, Guo ZJ, Chen PY, Schmidt AM, Miyata T, Zhang X: Enhanced expression of receptor for advanced glycation end products in chronic kidney disease. J Am Soc Nephrol 2004;15:1889-1896.

11 Schmidt AM, Yan SD, Yan SF, Stern DM: The biology of the receptor for advanced glycation end products and its ligands. Biochim Biophys Acta 2000;1498:99-111.

12 Rosenberg S, Elashoff MR, Beineke P, Daniels SE, Wingrove JA, Tingley WG, Sager PT, Sehnert AJ, Yau M, Kraus WE, Newby LK, Schwartz RS, Voros S, Ellis SG, Tahirkheli N, Waksman R, McPherson J, Lansky A, Winn ME, Schork NJ, Topol EJ: Multicenter validation of the diagnostic accuracy of a blood-based gene expression test for assessing obstructive coronary artery disease in nondiabetic patients. Ann Intern Med 2010;153:425-434.

13 Hofmann Bowman MA, Gawdzik J, Bukhari U, Husain AN, Toth PT, Kim G, Earley J, McNally EM: S100A12 in vascular smooth muscle accelerates vascular calcification in apolipoprotein e-null mice by activating an osteogenic gene regulatory program. Arterioscler Thromb Vasc Biol 2011;31:337-344.

14 Kosaki A, Hasegawa T, Kimura T, Iida K, Hitomi J, Matsubara H, Mori Y, Okigaki M, Toyoda N, Masaki H, Inoue-Shibata M, Nishikawa M, Iwasaka T: Increased plasma S100A12 (EN-RAGE) levels in patients with type 2 diabetes. J Clin Endocrinol Metab 2004;89:5423-5428.

15 Mori Y, Kosaki A, Kishimoto N, Kimura T, Iida K, Fukui M, Nakajima F, Nagahara M, Urakami M, Iwasaka T, Matsubara H: Increased plasma S100A12 (EN-RAGE) levels in hemodialysis patients with atherosclerosis. Am J Nephrol 2009;29:18-24.

16 DeLoach SS, Mohler ER 3rd: Peripheral arterial disease: a guide for nephrologists. Clin J Am Soc Nephrol 2007;2:839-846.

17 O'Hare AM, Glidden DV, Fox CS, Hsu CY: High prevalence of peripheral arterial disease in persons with renal insufficiency: results from the national health and nutrition examination survey 19992000. Circulation 2004;109:320-323.

18 Wattanakit K, Folsom AR, Selvin E, Coresh J, Hirsch AT, Weatherley BD: Kidney function and risk of peripheral arterial disease: results from the atherosclerosis risk in communities (ARIC) study. J Am Soc Nephrol 2007;18:629-636.

19 Stenvinkel P: Inflammatory and atherosclerotic interactions in the depleted uremic patient. Blood Purif 2001; 19:53-61.

20 Hofmann MA, Drury S, Fu C, Qu W, Taguchi A, Lu Y, Avila C, Kambham N, Bierhaus A, Nawroth P, Neurath MF, Slattery T, Beach D, McClary J, Nagashima M, Morser J, Stern D, Schmidt AM: RAGE mediates a novel proinflammatory axis: a central cell surface receptor for S100/calgranulin polypeptides. Cell 1999;97:889-901.

21 Shiotsu Y, Mori Y, Nishimura M, Sakoda C, Tokoro T, Hatta T, Maki N, Iida K, Iwamoto N, Ono T, Matsuoka E, Kishimoto N, Tamagaki K, Matsubara H, Kosaki A: Plasma S100A12 level is associated with cardiovascular disease in hemodialysis patients. Clin J Am Soc Nephrol 2011;6:718-723.

22 Nakashima A, Carrero JJ, Qureshi AR, Miyamoto T, Anderstam B, Barany P, Heimburger O, Stenvinkel P, Lindholm B: Effect of circulating soluble receptor for advanced glycation end products (sRAGE) and the proinflammatory RAGE ligand (EN-RAGE, S100A12) on mortality in hemodialysis patients. Clin J Am Soc Nephrol 2010;5:2213-2219.

23 Gawdzik J, Mathew L, Kim G, Puri TS, Hofmann Bowman MA: Vascular remodeling and arterial calcification are directly mediated by S100A12 (EN-RAGE) in chronic kidney disease. Am J Nephrol 2011;33:250-259.

24 Okamoto K, Oka M, Maesato K, Ikee R, Mano T, Moriya H, Ohtake T, Kobayashi S: Peripheral arterial occlusive disease is more prevalent in patients with hemodialysis: comparison with the findings of multidetector-row computed tomography. Am J Kidney Dis 2006;48:269-276.

25 de Vinuesa SG, Ortega M, Martinez P, Goicoechea M, Campdera FG, Luno J: Subclinical peripheral arterial disease in patients with chronic kidney disease: prevalence and related risk factors. Kidney Int Suppl 2005;S44-S47. 